\title{
Repeat induced abortion and associated factors among women seeking abortion care services at Debre Markos town health institutions, Amhara regional state, Ethiopia, 2017
}

\author{
Mahlet Imana Waktola', Dawit Gebeyehu Mekonen ${ }^{2 *} \mathbb{0}$, Tewodros Seyoum Nigussie²,
} Endeshaw Adimasu Cherkose ${ }^{2}$ and Addisu Taye Abate ${ }^{3}$

\begin{abstract}
Objective: The aim of this study was to assess the proportion and determinants of repeat induced abortion among women seeking abortion care services at Debre Markos town health institutions, Amhara regional state, Ethiopia, 2017.

Result: From the total 567-sample size, 547 women were participated in the study making a response rate of 96.5\%. In this study 191 women reported that they had at least one previous abortion, making the proportion of repeat induced abortion 34.9\%. In multivariable logistic regression analysis; illiteracy ( $\mathrm{AOR}=8.45,95 \% \mathrm{Cl} 1.85,36.49$ ), living in an urban area $(A O R=5.14,95 \% \mathrm{Cl} 2.29,11.53)$, having multiple sexual partner $(A O R=6.16,95 \% \mathrm{Cl} 3.25,11.68)$, consuming alcohol $(\mathrm{AOR}=2.77,95 \% \mathrm{Cl} 1.52,5.05)$ and having a history of physical violence by a male partner $(A O R=2.68,95 \% \mathrm{Cl} 1.45,4.94)$ were significantly associated with repeat induced abortion at $p$ value less than 0.05 .
\end{abstract}

Keywords: Repeat induced abortion, Cross-sectional study, Debre Markos town

\section{Introduction}

Induced abortion (IA) is a deliberate surgical or medical termination of pregnancy that has not reached viability and includes both safe and unsafe abortions [1].

Globally, the annual estimation of IA that occurred from 2010 to 2014 was 56 million. Fifteen percent (8.3 million) of this IAs had occurred In Africa, and 2.7 million IA had occurred in East Africa. In 2014, there was an estimated number of 620,300 IA in Ethiopia, with an annual rate of 28 abortions per 1000 reproductive age

\footnotetext{
${ }^{*}$ Correspondence: davegeby@gmail.com

${ }^{2}$ College of Medicine and Health Sciences, School of Midwifery,

University of Gondar, Gondar, Ethiopia

Full list of author information is available at the end of the article
}

women [2-5]. RIA accounts for a significant proportion of all IA in many countries, with reports ranging from 16 to $71 \%[1,6]$. In Ethiopia it accounts for 30 to 34 percent of all IA [7-9].

Termination of pregnancy in the first and second trimesters is associated with an increased risk of subsequent preterm birth, especially when performed with mechanical dilation and curettage or when performed repeatedly. Moreover, mid trimester pregnancy loss is more common in women who have had two or more induced or spontaneous abortions [10].

In Ethiopia, the number of women receiving treatment for complications from an abortion performed outside as well as inside a health institution increased between 2008 and 2014, rising from 52,600 to 103,600 [5]. 
Several measures have tried to prevent the impact of IA in Ethiopia. The major measure taken was providing post abortion care (PAC) as a response to avert deaths and injuries from abortion complications. Post abortion family planning (PAFP), a key component of PAC, has been provided specifically targeting to prevent repeat unintended pregnancies and repeat safe and unsafe abortions [11]. The International Conference on Population and Development (ICPD) Program of Action states that, "In no case should abortion be promoted as a method of family planning (FP)" [12]. Nevertheless, facts on unintended pregnancy and abortion in Ethiopia states that younger women who want to space births are using IA [13].

Despite the efforts to improve FP access and PAC specifically PAFP, the higher magnitude of repeat abortion in Ethiopia is worrisome. Furthermore, there is no study done on RIA and associated factor in Amhara region. Even if there are few studies done in Addis Ababa the capital city of Ethiopia, the available knowledge is insufficient to answer the relation of partner physical violence and substance exposure with RIA. Therefore, this study aimed to assess the magnitude and associated factors of RIA in Debre Markos town, Amhara region, Ethiopia.

\section{Main text \\ Methods \\ Study design and period}

An institutional based quantitative cross sectional study was conducted from October 1 to November 30, 2017 GC at health facilities of Debre Markos town, Amhara region, Ethiopia.

\section{Source and study population}

All reproductive aged women who seek abortion care services at health institutions of Debre Markos town were the study population, and those who seek the service at the selected health institutions of the town, during the study period, were the study population. Women on therapeutic abortion or those who had spontaneous abortion and came to the institution for PAC service were assumed to be excluded from the study.

\section{Sample size and sampling procedure}

The final sample size, 567, was calculated using single population proportion formula with the assumptions of 95\% confidence interval, $5 \%$ margin of error, $33.6 \%$ magnitude of RIA in Addis Ababa from a previous study [9], $10 \%$ non-response and a design effect of 1.5. Multi stage sampling was the technique used to select the study participants. First, by using cluster sampling technique, health facilities with safe abortion service were clustered based on facility ownership as public, non-governmental and private facilities. There were five public health facilities (four public health centers and one public referral hospital), two facilities owned by Non-Governmental Organizations (NGO) and six private clinics in the town. By simple random sampling technique, two public, one $\mathrm{NGO}$ and four private health facilities were selected from each cluster. After allocating proportional sample for each cluster, based on their average monthly abortion service, systematic random sampling technique was finally employed to select the study participants from each health institution. The sampling interval $\mathrm{K}$ was calculated by using the formula $\mathrm{K}=\mathrm{N} / \mathrm{n}$, and every second women was selected from each facility.

\section{Data collection tool and procedures}

The data was collected using an interviewer-administered questionnaire. It was conducted by eight diploma midwifes and supervised by four first degree holder midwifes. Prior to the data collection, proper training about the instrument and how to get consent for interview was given to the data collectors and supervisors for 3 days. The data collection tool was prepared from literatures, and first it was translated from English to the native language of the region (Amharic), and then re-translated to English language to ensure consistency. Moreover, pretest was conducted on 28 women who came for safe abortion service at University of Gondar referral hospital, Gondar town. Thereby, relevant modification was done to ensure the relevancy of the instrument before the actual data collection. The questionnaire contains; Part I-socio-demographic characteristics, Part II-sexual and reproductive health history, Part III-FP use and fertility intentions, Part IV-substance exposure status and Part V-gender based violence.

\section{Operational definition}

Repeat induced abortion-refers for the women who is having pregnancy termination for more than one time, without any medical or surgical indication.

\section{Statistical analysis}

First, the data was coded, entered and cleaned using Epi info statistical software version 7 . Then, it was exported to SPSS statistical software version 20 for analysis. Descriptive statistical analysis such as simple frequencies, measures of central tendency and measures of variability were used to describe the characteristics of participants. To see the association between each independent variable with the outcome variable, bivariate logistic regression was used, and variables with a $\mathrm{p}$ value $<0.2$ were selected for multivariable logistic regression. Independent predictors of RIA were determined by Multivariable logistic 
regression, and crude and adjusted odds ratios (COR \& AOR) together with their corresponding 95\% confidence intervals were computed to see the strength of association. Finally, level of statistical significance was declared at $\mathrm{p}$-value $<0.05$.

\section{Result}

\section{Socio-demographic characteristics}

Out of the total 567 sample size, 547 women were participated in the study making a response rate of $96.5 \%$. The mean age of the participants was $23.98( \pm 4.27)$ years and $42.6 \%$ of the participants were in the age group of $20-24$ years. Half of the participants had an educational level of more than secondary (50.1\%) and the majority (82.6\%) was urban residents (Table 1 ).

\section{Sexual and reproductive characteristics}

In this study, 191 women (34.9\%) had RIA (95\% CI (30.7$38)$ ), and the majority (91.6\%) had only one previous abortion. From the total study participants, most of them (78.6\%) had their pregnancy unplanned and unwanted. Only $31.8 \%$ of the participants had gave birth previously. Over half $(60.1 \%)$ received a PAFP method before they left the facility, and $47.2 \%$ and $72.5 \%$ of the participants reported a history of physical and sexual violence by their male partners, respectively (Table 2).

\section{Factors associated with RIA}

Five variables were significantly associated with RIA on multivariable logistic regression. Educational status had an association with the outcome variable. Participants with no education ( $\mathrm{AOR}=8.45,95 \%$ CI 1.85 , 36.49 ), with primary educational level (AOR $=5.46,95 \%$ CI 2.06, 14.47) and with secondary educational level $(\mathrm{AOR}=12.96,95 \%$ CI 6.16, 27.29) were $1.85,5.46$ and 12.96 times more likely to have RIA compared to those who were above secondary educational level. Compared to rural residents, Woman who were urban residents, had 5.14 times chance of RIA (AOR $=5.14,95 \%$ CI 2.29 , 11.53). Woman who had multiple sexual partner were 6.16 times more likely to have RIA compared to their counter parts $(\mathrm{AOR}=6.16,95 \%$ CI 3.25, 11.68). Alcohol consuming woman had 2.77 times more chance to experience RIA compared to non-users (AOR $=2.77,95 \% \mathrm{CI}$ $1.52,5.05)$. Woman who had physical violence by a male partner had 2.68 times more chance of engaging in RIA than those who had not $(\mathrm{AOR}=2.68,95 \%$ CI $1.45,4.94)$ (Table 3).
Table 1 Socio-demographic characteristics and substance exposure status of women who seek abortion care services at Debremarkos town health institutions, $2017(\mathrm{~N}=547)$

\begin{tabular}{|c|c|c|}
\hline Variables & Frequency & Percentage \\
\hline \multicolumn{3}{|l|}{ Age } \\
\hline $15-19$ & 88 & 16.1 \\
\hline $20-24$ & 233 & 42.6 \\
\hline $25-29$ & 186 & 34.0 \\
\hline $30-34$ & 40 & 7.3 \\
\hline \multicolumn{3}{|l|}{ Religion } \\
\hline Orthodox & 490 & 89.6 \\
\hline Muslim & 5 & 0.9 \\
\hline Protestant & 52 & 9.5 \\
\hline \multicolumn{3}{|l|}{ Ethnic group } \\
\hline Amhara & 527 & 96.3 \\
\hline Oromo & 12 & 2.2 \\
\hline Tigrie & 8 & 1.5 \\
\hline \multicolumn{3}{|l|}{ Place of residence } \\
\hline Urban & 452 & 82.6 \\
\hline Rural & 95 & 17.4 \\
\hline \multicolumn{3}{|l|}{ Level of education } \\
\hline No education & 46 & 8.4 \\
\hline Primary & 80 & 14.6 \\
\hline Secondary & 147 & 26.9 \\
\hline More than secondary & 274 & 50.1 \\
\hline \multicolumn{3}{|l|}{ Marital status } \\
\hline Married & 61 & 11.2 \\
\hline Single & 404 & 73.8 \\
\hline Divorced/separated/widowed & 82 & 15.0 \\
\hline \multicolumn{3}{|l|}{ Occupation } \\
\hline Unemployed & 67 & 12.2 \\
\hline Student & 157 & 28.7 \\
\hline Daily laborer & 160 & 29.3 \\
\hline Merchant & 71 & 13.0 \\
\hline Other & 92 & 16.8 \\
\hline \multicolumn{3}{|l|}{ Total monthly income } \\
\hline$<500$ & 201 & 37.9 \\
\hline $501-1000$ & 230 & 43.4 \\
\hline $1001-2000$ & 70 & 13.2 \\
\hline $2001-3000$ & 25 & 4.7 \\
\hline$>3001$ & 4 & 0.8 \\
\hline \multicolumn{3}{|l|}{ Ever smoke cigarette } \\
\hline Yes & 3 & 0.6 \\
\hline No & 544 & 99.4 \\
\hline \multicolumn{3}{|l|}{ Ever chew khat } \\
\hline Yes & 10 & 1.8 \\
\hline No & 537 & 98.2 \\
\hline \multicolumn{3}{|l|}{ Ever drink alcohol } \\
\hline Yes & 337 & 61.6 \\
\hline No [1] & 210 & 38.4 \\
\hline
\end{tabular}


Table 2 Sexual and reproductive health characteristics of women who seek abortion care services at Debre Markos town health institutions, $2017(\mathrm{~N}=547)$

\begin{tabular}{|c|c|c|}
\hline Variables & Frequency & Percentage \\
\hline \multicolumn{3}{|c|}{ Had multiple sexual partner } \\
\hline Yes & 245 & 44.8 \\
\hline No & 302 & 55.2 \\
\hline \multicolumn{3}{|c|}{ Total no of past pregnancies } \\
\hline 0 & 251 & 46 \\
\hline 1 & 167 & 30.5 \\
\hline 2 & 62 & 11.3 \\
\hline$\geq 3$ & 67 & 12.2 \\
\hline \multicolumn{3}{|c|}{ Ever gave birth } \\
\hline Yes & 174 & 31.8 \\
\hline No & 373 & 68.2 \\
\hline \multicolumn{3}{|c|}{ Total no of living biological children } \\
\hline 0 & 373 & 68.2 \\
\hline 1 & 93 & 17.0 \\
\hline 2 & 42 & 7.7 \\
\hline$\geq 3$ & 39 & 7.1 \\
\hline \multicolumn{3}{|c|}{ History of abortion } \\
\hline Yes & 191 & 34.9 \\
\hline No & 356 & 65.1 \\
\hline \multicolumn{3}{|c|}{ Number of previous abortions $(n=191)$} \\
\hline 1 & 175 & 91.6 \\
\hline 2 & 16 & 8.4 \\
\hline \multicolumn{3}{|c|}{ Termination method of previous abortion $(n=191)$} \\
\hline Medication & 150 & 78.5 \\
\hline Surgically & 41 & 21.5 \\
\hline \multicolumn{3}{|c|}{ Ever use FP method } \\
\hline Yes & 272 & 49.7 \\
\hline No & 275 & 50.3 \\
\hline \multicolumn{3}{|l|}{ Current FP use } \\
\hline Yes & 140 & 25.6 \\
\hline No & 407 & 74.4 \\
\hline \multicolumn{3}{|c|}{ Receive FP counseling during this visit } \\
\hline Yes & 546 & 99.8 \\
\hline No & 1 & 0.2 \\
\hline \multicolumn{3}{|c|}{ Desire for children in the future } \\
\hline Yes & 453 & 82.8 \\
\hline No & 94 & 17.2 \\
\hline \multicolumn{3}{|c|}{ History of physical violence by male partner } \\
\hline Yes & 258 & 47.2 \\
\hline No & 289 & 52.8 \\
\hline \multicolumn{3}{|c|}{ History of sexual violence by male partner } \\
\hline Yes & 395 & 72.2 \\
\hline No & 152 & 27.8 \\
\hline
\end{tabular}

\section{Discussion}

The overall magnitude of RIA for this study was $34.9 \%$ (95\% CI (30.7-38.8)), the result is found to be comparable with two studies conducted at public and Non-governmental health institutions of Addis Ababa city, Ethiopia, $31 \%$ and $33.6 \%[8,9]$.

The figure however is slightly higher than a study done in Kenya and Nigeria with magnitude of RIA 16\% and $23 \%$ respectively $[1,14]$. This might be due to the liberalized abortion law in Ethiopia may encourage women to seek for abortion care in a health institution. On the contrary, this study has smaller magnitude compared to the study done in Tunisia (42.2\%) [15]. This may be due to the long time history of the liberalization of abortion law in Tunisia. Furthermore, this study has a much lower figure compared to two studies conducted in United States of America (USA) in New York (57\%) and San Francisco $(59 \%),[16,17]$. This may be due to the relatively better development stage of the country may contribute to better reporting of previous abortions.

Our study has identified that participants who had no education and had an educational level of primary and secondary were more likely to undergo a RIA than those who had an educational level of more than secondary. The finding is in consistent with the study in Ethiopia, Kenya, Tunisia, Georgia, and Russia [1, 8, 15, 18, 19]. Unplanned pregnancy secondary to poor contraceptive knowledge and use among those with a lower educational level might be the possible reason.

This study has found out urban residents had five time higher risk of having RIA than rural residents. This finding is consistent with the study done in Kenya [20]. This may be due to the low institutional service utilization of woman from rural area, and rather than seeking for safe abortion, they may choose to use unsafe abortion to terminate the pregnancy that reduces the figure.

In this study, woman who had multiple sexual partner were 2.68 times more likely to have a RIA than those who did not. This finding is consistent with the study done in Addis Ababa, Ethiopia and in Britain [8, 21]. This could be due to the fact that having multiple sexual partners will make those women to be in an unstable relationship, which leads to irregular use of contraceptive that will cause contraceptive failure and unwanted pregnancy.

This study has identified an association between alcohol use and RIA. Those who were consuming alcohol had a 2.7 times higher risk of having a RIA. This finding is consistent with the research done in San Francisco General Hospital, USA and with the study done in Russia $[17,19]$. This may be because of the impact of alcohol on logical thinking of women and might lead them to have unprotected sex.

Finally, those who had a history of physical violence by a male partner had a 2.6 times higher risk of having a RIA than those who did not have a history of physical violence. This result is consistent with the studies done in 
Table 3 Bivariate and multivariable logistic regression analysis of determinants of repeat induced abortion among women who seek abortion care services at Debre Markos town health institutions, $2017(\mathrm{~N}=547)$

\begin{tabular}{|c|c|c|c|c|}
\hline \multirow[t]{2}{*}{ Variables } & \multicolumn{2}{|c|}{ Repeat abortion } & \multirow[t]{2}{*}{ COR $(95 \% \mathrm{Cl})$} & \multirow[t]{2}{*}{ AOR $(95 \% \mathrm{CI})$} \\
\hline & Yes (\%) & No (\%) & & \\
\hline \multicolumn{5}{|l|}{ Place of residence } \\
\hline Urban & $172(90.1)$ & $280(78.7)$ & $2.457(1.436,4.205)$ & $5.141(2.291,11.536)^{* *}$ \\
\hline Rural [1] & $19(9.9)$ & $76(21.3)$ & 1 & 1 \\
\hline \multicolumn{5}{|l|}{ Level of education } \\
\hline No education & $15(7.9)$ & $31(8.7)$ & $1.153(0.591,2.250)$ & $8.452(1.856,36.491)^{*}$ \\
\hline Primary & $25(13.1)$ & $55(15.4)$ & $1.083(0.632,1.857)$ & $5.462(2.061,14.478)^{*}$ \\
\hline Secondary & 70 (36.6) & $77(21.6)$ & $2.166(1.431,3.280)$ & $12.966(6.160,27.29)^{* *}$ \\
\hline More than secondary & $81(42.4)$ & $193(54.2)$ & 1 & 1 \\
\hline \multicolumn{5}{|c|}{ Had multiple sexual partner } \\
\hline Yes & $126(66.0)$ & $119(33.4)$ & $3.861(2.662,5.598)$ & $6.162(3.251,11,680)^{* *}$ \\
\hline No [1] & $65(34.0)$ & $237(66.6)$ & 1 & 1 \\
\hline \multicolumn{5}{|l|}{ Ever gave birth } \\
\hline Yes & 70 (36.6) & $104(29.2)$ & 1 & 1 \\
\hline No [1] & $121(63.4)$ & $252(70.8)$ & $0.713(0.491,1.035)$ & - \\
\hline \multicolumn{5}{|l|}{ Ever use FP method } \\
\hline Yes & $114(59.7)$ & $158(44.4)$ & 1 & 1 \\
\hline No [1] & $77(40.3)$ & $198(55.6)$ & $0.539(0.377,0.770)$ & - \\
\hline \multicolumn{5}{|l|}{ Current FP use } \\
\hline Yes & $59(30.9)$ & $81(22.8)$ & 1 & 1 \\
\hline No [1] & $132(69.1)$ & $275(77.2)$ & $0.659(0.444,0.978)$ & - \\
\hline \multicolumn{5}{|l|}{ Ever drink alcohol } \\
\hline Yes & $149(78.0)$ & $188(52.8)$ & $3.17(2.124,4.733)$ & $2.774(1.523,5.051)^{*}$ \\
\hline No [1] & $42(22.0)$ & $168(47.2)$ & 1 & 1 \\
\hline \multicolumn{5}{|l|}{ Physical violence } \\
\hline Yes & $120(62.8)$ & $138(38.8)$ & $2.67(1.858,3.837)$ & $2.680(1.453,4.943)^{*}$ \\
\hline No [1] & $71(37.2)$ & $218(61.2)$ & 1 & 1 \\
\hline \multicolumn{5}{|l|}{ Sexual violence } \\
\hline Yes & $152(80.0)$ & $243(68.5)$ & $1.844(1.211,2.806)$ & - \\
\hline No [1] & $38(20.0)$ & $112(31.5)$ & 1 & 1 \\
\hline
\end{tabular}

1 Reference category

*Variables which are significantly associated with RIA ( $p$-value $<0.05) .{ }^{* *}$ Variables which are significantly associated with RIA ( $p$-value $\left.<0.001\right)$

Tunisia [15]. This could be due to fear of telling her male partner about the pregnancy and tend to protect herself by having an induced abortion.

\section{Conclusion}

In nutshell, this study revealed a high rate of RIA in Debre Markos town health institutions. Upon the identified factors, it is required from health programmers and different NGOs to create awareness about the impact of RIA among those who are living in urban areas, has multiple sexual partner and less educated and students through mass media. Moreover, consider providing a youth friendly FP service at school clinics including primary and secondary schools. Rehabilitation centers and social support groups need to be widely accessible for alcohol users.

\section{Limitation}

Due to the sensitivity of this issue, participants may tend to under report history of past abortion.

\footnotetext{
Abbreviations

AOR: adjusted odds ratio; Cl: confidence interval; COR: crud odds ratio; Epi info: statistical package for epidemiological information analysis; FP: family planning; GC: Gregorian calendar; IA: induced abortion; ICPD: International Conference on Population and Development; NGO: Non-Governmental Organization; PAC: post abortion care; PAFP: post abortion family planning; PI: principal investigator; RIA: repeat induced abortion; SPSS: statistical package for social science; USA: United States of America.
} 


\section{Acknowledgements}

We are very grateful to the University of Gondar for approval of the ethical clearance, technical and financial support of this study. We are also grateful to the Debre Markos town health institutions administrators for their permission and collaboration during the data collection process.

\section{Authors' contributions}

MIW involved in the conception and design of the study, participated in data collection, analyzed the data, drafted the manuscript and approve the final version of the manuscript. DGM, TSN, EAC, and ATA approved the proposal with some revisions, participated in data analysis and interpretation, in revising subsequent drafts of the manuscript and approve the last version of the manuscript. All authors read and approved the final manuscript.

\section{Funding}

The funding source of this research was from the University of Gondar and the University has no role in design, data collection, analysis, decision to publish as well as preparation of the manuscript.

\section{Availability of data and materials}

To keep patients' confidentiality, the raw data would not be shared. But, it is available from the corresponding author on reasonable request and the summary data are available in the main document.

\section{Ethics approval and consent to participate}

Ethical clearance was obtained from the Department of Midwifery under the delegation from Ethical Review Board of the University of Gondar. An official letter of permission was obtained from Debre Markos Town, City Administration Health Office, for entry to each health institutions. Written consent was obtained from each study participants after informing the objective of the study. For participants under the age of 18 , the consent was taken from their parent or guardian. In the consent form, statements about potential risk, benefit, and confidentiality were included.

\section{Consent for publication}

Not applicable.

\section{Competing interests}

The authors declare that they have no competing interests.

\section{Author details}

${ }^{1}$ College of Health, Department of Midwifery, Mizan Tepi University, Mizan Tepi, Ethiopia. ${ }^{2}$ College of Medicine and Health Sciences, School of Midwifery, University of Gondar, Gondar, Ethiopia. ${ }^{3}$ College of Medicine and Health Sciences, School of Nursing, Department of Medical Nursing, University of Gondar, Gondar, Ethiopia.

Received: 3 October 2019 Accepted: 14 January 2020

Published online: 28 January 2020

\section{References}

1. Maina BW, Mutua MM, Sidze EM. Factors associated with repeat induced abortion in Kenya. BMC Public Health. 2015;15:1-20.

2. Moore AM, Gebrehiwot Y, Fetters T, Wado YD, Bankole A, Singh S, Gebreselassie $H$, Getachew $Y$. The estimated incidence of induced abortion in Ethiopia, 2014: changes in the provision of services since 2008. Int Perspect Sex Reprod Health. 2016;42(3):111.
3. Guttmacher Inst. Induced abortion worldwide, fact sheet. New York: Guttmacher Inst; 2016.

4. Guttmacher Inst. Abortion in Africa, fact sheet. New York: Guttmacher Inst; 2016. p. 1-2.

5. Guttmacher Inst. Induced abortion and postabortion care in Ethiopia, fact sheet. Ipas: Guttmacher Institute; 2017.

6. Thi N, Huong M, Chongsuvivatwong V, Geater A, Prateepchaikul L, Unit E, et al. Characteristics of repeat aborters in Vietnam. South East Asian J TROP MED Public Health. 2000;31(1):167.

7. Prata N, Holston M, Fraser A, Melkamu Y. Contraceptive use among women seeking repeat abortion in Addis Ababa Ethiopia. African J Reprod Health. 2013;17(4):56-65.

8. Getachew F. Determinants of repeat induced abortion in Addis Ababa. 2014.

9. Alemayehu B, Addissie AAW. The magnitude and associated factors of repeat induced abortion among women of reproductive age group who seek abortion care services at Marie Stopes International Ethiopia clinics in Addis Ababa, Ethiopia; 2015.

10. DeCherney AH, Nathan L, Laufer N, Roman AS. Contraception and family planning current diagnosis and treatments in obstetrics and gynecology. 10th edn. United States: The McGraw-Hill Companies; 2007.

11. Turner $\mathrm{KL}$, Huber A. Woman-centered postabortion care reference manual. Ipas. 2nd edn; 2013.

12. Ls A. What was Cairo? The promise and reality of ICPD. Washington D.C. Population Reference Bureau; 2004

13. Guttmacher Inst. Facts on unintended pregnancy and abortion in Ethiopia. New York: Guttmacher Inst; 2010.

14. Lamina MA. Prevalence of abortion and contraceptive practice among women seeking repeat induced abortion in Western Nigeria. J Pregnancy. 2015;15:40.

15. El Mhamdi S, Salah AB, Bouanene I, Hlaiem I, Hadhri S, Maatouk W. Obstetric and psychological characteristics of women seeking multiple abortions in the region of Monastir (Tunisia): results of a cross-sectional design. BMC Womens Health. 2015;15(40):1-6.

16. Toprani A, Li W, Sackoff J, Greene C, Elizabeth B. Erratum to: repeat abortions in New York City, 2010. J Urban Health. 2015;92(3):11524.

17. Prager SW, Steinauer JE, Foster DG, Darney PD, Drey EA. Risk factors for repeat elective abortion. Am J Obs Gynecol. 2007;197(575):e1-6.

18. Pestvenidze E, Berdzuli N, Lomia N, Gagua T, Umikashvili L, Stray-Pedersen B. Repeat induced abortions in Georgia, characteristics of women with multiple pregnancy terminations: secondary analysis of the Reproductive Health Survey 2010. Eur J Obstet Gynecol Reprod Biol. 2016;205:85-90.

19. Keenan K, Grundy E, Kenward MG, Leon DA, Michael G, Women DA, et al. Women â $€^{\mathrm{TM}}$ s risk of repeat abortions is strongly associated with alcohol consumption: a longitudinal analysis of a Russian national panel study, 1994-2009. PLoS ONE. 2014:9(3):1932-6203.

20. Kabiru CW, Ushie BA, Mutua MM, Izugbara CO. Previous induced abortion among young women seeking abortion-related care in Kenya : a crosssectional analysis. BMC Pregnancy Childbirth. 2016;16(104):1-10. https:// doi.org/10.1186/s12884-016-0894-z.

21. Stone N, Ingham R. Who presents more than once? Repeat abortion among women in Britain. J Fam Plann Reprod Health Care. 2011;37:209-15.

\section{Publisher's Note}

Springer Nature remains neutral with regard to jurisdictional claims in published maps and institutional affiliations. 